\title{
Process Intensification of The lonosolv Pretreatment: Effects Of Biomass Loading, Particle Size And 100-Fold Scale-Up
}

Clementine L. Chambon

Imperial College London

Pedro Verdía

Imperial College London

Paul S. Fennell

Imperial College London

Jason Hallett ( $\nabla$ j.hallett@imperial.ac.uk)

Imperial College London https://orcid.org/0000-0003-3431-2371

\section{Research}

Keywords: Miscanthus, ionic liquids, pretreatment, scale up, process intensification, particle size, biomass loading.

Posted Date: January 15th, 2021

DOl: https://doi.org/10.21203/rs.3.rs-144251/v1

License: (9) This work is licensed under a Creative Commons Attribution 4.0 International License.

Read Full License

Version of Record: A version of this preprint was published at Scientific Reports on July 28th, 2021. See the published version at https://doi.org/10.1038/s41598-021-94629-z. 


\section{Abstract}

Background: The ionoSolv process is one of the most promising technologies for biomass pretreatment in a biorefinery context. In order to evaluate the transition of the ionoSolv pretreatment of biomass from bench-scale experiments to biorefinery scale, there is a need to get better insight in process intensification. In this work, the effects of biomass loading, particle size, pulp washing protocols and 100fold scale up for the pretreatment of the grassy biomass Miscanthus giganteus with the IL triethylammonium hydrogen sulfate, [TEA][HSO $\left.{ }_{4}\right]$, are presented.

Results: At the bench scale, increasing biomass loading from $10 \mathrm{wt} \%$ to $50 \mathrm{wt} \%$ reduced glucose yields from $68 \%$ to $23 \%$ due to re-precipitation of lignin onto the pulp surface. Omitting the pulp air-drying step maintained saccharification yields at $66 \%$ at $50 \mathrm{wt} \%$ loading due to reduced fiber hornification. 100 -fold scale-up (from $10 \mathrm{~mL}$ to $1 \mathrm{~L}$ ) improved the efficacy of ionoSolv pretreatment and increasing loadings from $10 \mathrm{wt} \%$ to $20 \mathrm{wt} \%$ reduced lignin reprecipitation and led to higher glucose yields due to the improved heat and mass transfer caused by efficient slurry mixing in the reactor. Pretreatment of particle sizes of 1-3 $\mathrm{mm}$ was more effective than fine powders $(0.18-0.85 \mathrm{~mm})$ giving higher glucose yields due to reduced surface area available for lignin re-precipitation while reducing grinding energy needs.

Conclusion: Stirred ionoSolv pretreatment showed great potential for industrialization and further process intensification after optimization of the pretreatment conditions (temperature, residence time, stirring speed), particle size and biomass loading. Pulp washing protocols need further improvement to reduce the incidence of lignin precipitation and the water requirements of lignin washing.

\section{Background}

Chemical pretreatment is an essential step in the conversion of lignocellulosic materials to biofuels, chemicals and other products. After feedstock costs ( 30\%), it is considered the second most expensive step, representing $\sim 14 \%$ of conversion costs. ${ }^{1}$ Therefore, there is a need to reduce its associated costs. The ionic liquid (IL) cost, IL-to-biomass ratio (i.e. solids loading) and the IL recycling rate have been identified as focus areas for more cost-effective pretreatments. ${ }^{2}$ Our previous work has demonstrated that low-cost protic ILs (PIL) can deconstruct and fractionate hardwood, softwood and grassy biomass feedstocks, producing a highly digestible cellulose-rich pulp and lignin with tunable properties. ${ }^{3-5}$ The alkylammonium-based ILs used have high thermal stability and could be recycled multiple times, according to studies conducted at the bench scale (10-20 mL batch size without stirring). ${ }^{3}$

Here, we address three key remaining challenges to reduce costs of IL pretreatment by process intensification: (1) increasing biomass loading, to minimize the consumption of chemicals and reactor size; (2) increasing biomass particle size, reducing energy required to grind biomass; and (3) process scale-up, investigating pretreatment efficacy after introduction of stirring and the adaptation of pulp and lignin washing and recovery protocols to handle larger process volumes. 


\section{Biomass loading}

Reactor size and solvent cost scale approximately inversely with solids loading, leading to lower capital costs and energy requirements for heating and cooling, ${ }^{2,6-8}$ Doubling the solids loading can be expected to decrease reactor CAPEX by approximately $40 \%$, making this parameter essential to improve economic viability of pretreatments processes. ${ }^{9}$ However, high solids concentrations increase the viscosity of the biomass-IL slurry, ${ }^{10}$ introducing heat and mass transfer limitations and higher power requirements for stirring. 2,11,12 Most pretreatment studies at the bench scale are performed with solids loadings between 5-20 wt\% where pretreatment efficiency is high. Process intensification studies have mostly examined cellulose-dissolving ILs such as [Emim][OAc], finding trends of decreasing lignin removal efficiency and solid recoveries during switchgrass pretreatment. ${ }^{10}$ Saccharification yields decreased significantly above $20 \mathrm{wt} \%$ loading, beyond which point the IL was only able to wet the surface of the biomass, ceasing to act as a true solvent. ${ }^{10,13}$

ionoSolv processes are based on the dissolution of lignin and hemicelluloses (20-30 wt\% of biomass) but not of cellulose (the remaining 60-70 wt\%). 3,4 Viscosity is therefore less dependent on solids loading than for cellulose-dissolving ILs such as [Emim] [OAc]. ${ }^{10} \mathrm{Gschwend}$ et al. increased the solid to solvent ratio up to $50 \mathrm{wt} \%$ for pretreatment of pine using [DMBA][HSO$\left.{ }_{4}\right]$ at bench scale $(\sim 10 \mathrm{~mL})$, obtaining glucose yields of $75 \%$ after saccharification, compared to quantitative glucose release at $10 \mathrm{wt} \%$ loading. ${ }^{9}$ It is worthy to note that dissolution of lignin during ionoSolv treatment introduces the possibility of lignin re-depositing onto the cellulose surface. ${ }^{14-16}$ This raises the need to adapt pulp washing protocols to avoid lignin re-precipitation and hornification, both of which negatively affect enzymatic hydrolysis yields.

\section{Biomass size reduction}

Biomass grinding (comminution) is a highly energy-intensive operation routinely conducted as a first step in many bioconversion processes for transport and processing purposes. ${ }^{17-20}$ It has been estimated to account for up to $60 \%$ of the total energy of chemical pretreatment ${ }^{21}$ and $10 \%$ of the process cost. ${ }^{22}$ Hence, developing technologies capable of converting biomass with larger particle sizes is highly desirable and has been investigated using leading pretreatment technologies. ${ }^{23,24-26}$ Larger particles lead to slower penetration of IL into biomass and slower dissolution of biomass components, but also reduce viscosity of the slurry and power requirements for stirring. ${ }^{27,28}$

Dilute acid and alkaline treatments have been found to perform best at a maximal particle size of $3 \mathrm{~mm}$, whereas liquid hot water $(15 \mathrm{~mm})$ and steam explosion $(50 \mathrm{~mm})$ offer more flexibility for pretreating large particle sizes. ${ }^{21,24}$ Studies of cellulose-dissolving ILs were found to maintain high glucose yields using feedstock size of up to $5 \mathrm{~mm}$ for rice straw, $6 \mathrm{~mm}$ for woody biomass, and $12.5 \mathrm{~mm}$ for corn stover. ${ }^{26,29-33}$ Among lignin-dissolving ILs, cholinium lysinate, [Ch][Lys] showed high delignification ability for corn stover up to $10 \mathrm{~mm}$ at solids loading of $50 \mathrm{wt} \%{ }^{29,31}$ Hardwoods and softwoods, which 
have higher density and lignin content, are significantly more energy-intensive to grind and are expected to be more sensitive to particle size than grassy feedstocks. ${ }^{19,21,24,34}$

\section{Process scale-up}

So far, the scale-up of IL pretreatment processes has been focused on cellulose-dissolving ILs. ${ }^{35,36}$ Pretreatment of switchgrass was scaled up 600 -fold ( $6 \mathrm{~L}$ vs $0.01 \mathrm{~L}$ ) by Li et al. ${ }^{35}$ using $15 \mathrm{wt} \%$ biomass loading, maintaining high glucose release (95\%), similar pulp recoveries and higher delignification. The main challenge was removing residual IL from the recovered pulp, requiring excessive water and waterethanol washes, as IL can act as an inhibitor to saccharification enzymes and yeasts in fermentation downstream. ${ }^{35,37,38}$ With hardwood and mixed feedstocks (hardwood/grass) a 30-fold scale-up to $6 \mathrm{~L}$ gave less effective lignin and hemicellulose removal due to the combined effects of scale-up, loading (10 wt\%) and temperature severity. However, uniform mixing and more effective biomass washing and recovery by centrifugation increased the recovery of structural carbohydrates. ${ }^{39}$

To date, no scale-up studies of the ionoSolv process have yet been published, yet this process offers several advantages over cellulose-dissolving IL technologies. It uses IL-water mixtures of cheap ILs synthesized from low-cost amines and sulfuric acid at a price competitive with common organic solvents. ${ }^{40}$ These solvents have low viscosity, which facilitates handling, and are tolerant to feedstock moisture. ${ }^{41,42}$ In our previous works, the robustness of the ionoSolv pretreatment process to varying temperatures, IL cations, solids loadings and feedstocks has been verified over a wide range of conditions. ${ }^{41-44}$ However, the data obtained at the bench scale cannot be directly translated to industrially-relevant scales.

\section{Study design}

In this study, Miscanthus $\times$ giganteus was chosen as feedstock because it has been extensively studied in our laboratories and is considered suitable for large-scale biorefining, being geographically widespread and having low water and land requirements for cultivation. ${ }^{3,5,45}$ We initially focus on process intensification of Miscanthus pretreatment at the bench scale $(10 \mathrm{~mL})$ by increasing the biomass loading from $2 \mathrm{wt} \%$ to $50 \mathrm{wt} \%$ and the particle size from fine powder (smallest dimension $<1 \mathrm{~mm}$ ), to medium fibres ( $<2 \mathrm{~mm}$ ) to large chips $(<10 \mathrm{~mm})$. Adaptation of pulp washing protocols was explored to reduce lignin deposition onto the pulp surface. Finally, we investigate 100-fold scale-up in a 1-L stirred reactor while varying stirring speeds to improve heat and mass transfer. At this scale it was not possible to investigate loadings above $20 \mathrm{wt} \%$ due to limited stirrer motor power compatible with the acid-resistant glass reactors used. The outcome of all pretreatment experiments was assessed by gravimetric determination of the pulp and lignin yield, characterization of pulps by enzymatic saccharification and compositional analysis, and lignin analysis by HSQC NMR and GPC.

\section{Experimental}

\section{Materials And Method}


Miscanthus $\times$ giganteus was obtained from Imperial College London Silwood Park campus (Berkshire, UK) in December 2014 and April 2016. Each set of experiments were conducted with biomass prepared during a single harvesting batch (batches were not mixed). All biomass was air-dried and either manually chopped or comminuted using a hammer mill (Retch SM 2000) followed by sieving (Retsch AS 200) to the relevant size fraction. Unless otherwise indicated, biomass was size-reduced using the hammer mill and sieved to $0.18-0.85 \mu m(-20 /+80$ US mesh scale) as the standard particle size fraction.

Complete experimental details can be found in the ESI.

\section{lonic liquid synthesis (triethylammonium hydrogensulfate, [TEA][HSO $\left.{ }_{4}\right]$ )}

All pretreatment experiments in this study used a solution of $80 \mathrm{wt} \%$ [TEA][HSO ${ }_{4}$ ] with $20 \mathrm{wt} \%$ deionized water as pretreatment solvent. Experiments conducted at the $10 \mathrm{~mL}$ scale used [TEA][HSO ${ }_{4}$ ] synthesized in batches of $\sim 150 \mathrm{~g}$ following a method previously described, ${ }^{46}$ with the exception of benchmarking experiments carried out as a direct comparison of scale-up experiments. Larger quantities for all scale-up and benchmarking experiments were synthesized in a continuous stirred tank reactor (CSTR) designed and built for continuous production of $\sim 1 \mathrm{~kg} / \mathrm{h}$ protic ILs (further details in the ESI). The acidity of the IL solutions was measured with a pH meter (Mettler Toledo SevenEasy). The thermogravimetric analysis of dried fresh IL (containing $<0.5 \mathrm{wt} \%$ water as verified by Karl-Fischer titration) was performed on a TA Q500 (TA Instruments, USA) TGA analyzer.

\section{Standard operating procedure: $10 \mathrm{~mL}$ scale pretreatment}

For "bench scale" experiments ( $10 \mathrm{~g}$ of IL solution), ionoSolv pretreatment was carried out using a published standard operating procedure. ${ }^{46}$ Biomass to solvent ratios of between $1: 2$ and 1:50 g/g (2$50 \mathrm{wt} \%$ loading) were used and Miscanthus was pretreated for 6 hours at $120^{\circ} \mathrm{C}$ in sealed glass pressure tubes. After the pretreatment time had elapsed, the pulp was separated by centrifugation, washed ( $4 \mathrm{x}$ $40 \mathrm{~mL}$ per $\mathrm{g}$ of biomass) and Soxhlet extracted with ethanol ( $24 \mathrm{~h})$ and air dried. The ethanol was evaporated from the IL/ethanol mixture and lignin was precipitated by addition of deionized water ( 3 equivalents, defined as a ratio of water to IL solution of $3 \mathrm{~g} \cdot \mathrm{g}^{-1}$ ), isolated by centrifugation, washed two more times, dried in vacuo at $45^{\circ} \mathrm{C}$ overnight and weighed to determine the lignin yield.

For the hornification experiments, two triplicates sets of pretreated Miscanthus samples were subjected to the same ethanol washing steps until the Soxhlet step. In one set of triplicates, the pulp was air-dried after the Soxhlet extraction step and in the other it was washed with water and stored wet to avoid dryinginduced hornification.

\section{Alternative washing protocols}

For DMSO washing experiments, the pulps were first washed with ethanol ( $4 x 40 \mathrm{~mL})$ as in the standard procedure. After the fourth ethanol wash, they were incubated in $40 \mathrm{~mL}$ of DMSO overnight, centrifuged 
(3000 rpm, $50 \mathrm{~min}$ ), the DMSO decanted and the pulps were then Soxhlet extracted with ethanol following the standard procedure.

For experiments where pulps were saccharified without air-drying to avoid hornification, after the Soxhlet extraction step the pulps were left in the thimble inside a Falcon tube filled with DI water for one hour, centrifuged (3000 rpm, $50 \mathrm{~min}$ ), the supernatant decanted and the washing step was repeated once more in DI water. The pulps were weighed, their moisture content determined and saccharification run the following day.

\section{Particle size experiments}

Three sets of experiments with different particle sizes, prepared as explained in the ESI, were conducted for two different feedstock-solvent combinations: Miscanthus-[TEA][HSO $\left.{ }_{4}\right]\left(120^{\circ} \mathrm{C}, 6 \mathrm{~h}\right)$, and Miscanthusdilute acid $\left(3 \mathrm{wt} \% \mathrm{H}_{2} \mathrm{SO}_{4}, 120^{\circ} \mathrm{C}, 1.5 \mathrm{~h}\right.$ ). The standard pretreatment protocols for bench scale ionoSolv and dilute acid pretreatment, respectively, were followed.

\section{Benchmarking experiments}

Benchmarking experiments were carried out in $15 \mathrm{~mL}$ Ace glass pressure tubes without stirring, using identical pretreatment conditions as the scaled-up experiments below (see Table ESI-1).

\section{Standard operating procedure: $1 \mathrm{~L}$ scale pretreatment}

All scale-up reactions were carried out using the experimental set up described previously, ${ }^{5}$ employing an 'Ecoclave' pressure reactor system on a 1.5-L jacketed borosilicate glass pressure vessel (Type 2, rated to 6 barg, Büchi AG, Switzerland, Figure ESI-1). The reactor was loaded with either $100 \mathrm{~g}$ or $200 \mathrm{~g}$ of Miscanthus, on oven dried basis, for 10 or $20 \mathrm{wt} \%$ loadings, respectively and $1 \mathrm{~kg}$ of IL. The biomass-IL slurry was heated to $120^{\circ} \mathrm{C}$ with stirring at $150 \mathrm{rpm}$ (unless otherwise indicated) from an anchor impeller. After the reaction, the IL-pulp slurry was vacuum filtered and washed with ethanol $(10 \times 1 \mathrm{~L})$. The recovered IL and ethanol washes were concentrated by rotary evaporation until all ethanol had been removed. After ethanol removal, lignin was precipitated and washed with deionized water. The IL-water mixture remaining was collected and concentrated to determine the IL recovery rate. The recovered ethanol and water were separately collected and re-used in subsequent washing steps to reduce solvent wastage. Full experimental details, including a sample heating curve can be found in the ESI (Figure ESI2).

\section{Compositional analysis}

The compositions of the untreated biomass, pretreated pulps and precipitated lignins were determined according to the NREL protocol 'Determination of Structural Carbohydrates and Lignin in Biomass'. ${ }^{47}$ For pulps that were obtained both in hornified (dry) and non-hornified (wet) state, only the dried hornified pulps were analyzed by compositional analysis. The composition of the non-hornified pulps was assumed to be identical. For pretreated pulps arising from larger particle size experiments $(>0.85 \mathrm{~mm})$, 
the materials size was reduced to $\leq 0.85 \mathrm{~mm}$ before the analysis so they could be fully digested during the acid hydrolysis step.

\section{Saccharification assay}

Saccharification assays were carried out based on NREL protocol 'Enzymatic saccharification of lignocellulosic biomass' ${ }^{48}$ Experiments were run in triplicate using Cellic ${ }^{\circledR}$ CTec2 enzyme blend obtained from Novozymes (Denmark), an analytical enzyme mixture containing cellulases, ß-glucosidases, and hemicellulase, for degrading cellulose to fermentable sugars (20 $\mu \mathrm{L}$ per sample). Glucose concentrations were determined after 7 days. To determine the initial rate of hydrolysis, time-point samples were taken at intervals of $0.5,1,2,4,24$, and 72 hours. Glucose yields were reported as a percentage of the total glucan content found in untreated biomass.

\section{Particle size distribution measurements}

For all the particle size experiments, the particle size distributions were determined using nested sieves. The sample particle size distribution was obtained by shaking for 20 minutes on a vibratory sieve shaker equipped with stacked sieves with decreasing pore sizes. The percentage weight of material retained by each sieve was measured and the log-normal distribution mass median diameter $\left(D_{50}\right)$ was calculated. Particle size distributions were plotted as weight percentages of samples passing through different sieve pore sizes (on a log scale) and the geometric mean diameters $D_{50}$ were compared.

\section{Characterization of lignins}

HSQC experiments were recorded on a Bruker $600 \mathrm{MHz}$ spectrometer, using ca. $20 \mathrm{mg}$ of lignin and DMSO- $d_{6}$ as solvent, for lignins isolated from selected experiments. GPC measurements were performed using an Agilent 1260 Infinity instrument equipped with a Viscotek column set (AGuard, A6000M and A3000M).

\section{Elemental analysis}

Representative samples were selected from experiments conducted at $10 \mathrm{wt} \%$ and $50 \mathrm{wt} \%$ loadings. CHNS analysis of untreated air-dried biomass, pulp, lignin and recovered IL were performed in duplicate by MEDAC Ltd (Chobham, UK). Oxygen content was obtained by difference. Accuracy is $\pm 0.30 \%$ absolute. CHNSO compositions and the calculated elemental composition of fresh IL were presented on a dry basis and used to conduct an elemental mass balance on the systems.

\section{Results And Discussion}

The effect of increasing solids loading and particle sizes for pretreatment of Miscanthus $\times$ giganteus using the low-cost PIL [TEA][HSO $\left.{ }_{4}\right]$ was first examined at the bench scale in unstirred glass tubes (working volume of $10 \mathrm{~mL}$ ). The pulp recovery protocol was modified to improve saccharification yields 
at high solids loadings. These results constituted baseline data for comparison with scale-up runs. Then, process intensification was investigated by 100 -fold scale-up (working volume of $1 \mathrm{~L}$ ). Pretreatment efficacy was analyzed by comparing pulp and lignin yields, pulp composition, saccharification yields and kinetics, and lignin characteristics.

\section{Effect of biomass loading}

We assessed the pretreatment efficacy at loadings ranging from 2 to $50 \mathrm{wt} \%$, corresponding to solid to liquid ratios of $1: 50$ to $1: 2 \mathrm{~g} / \mathrm{g}$. These experiments were carried out under non-optimal conditions $\left(120^{\circ} \mathrm{C}\right.$, $6 \mathrm{~h}$ ) from the point of view of obtaining maximal glucose release in saccharification, where the differences in pretreatment efficacy would be easier to observe.

\section{Pulp, lignin and saccharification yields}

Increasing the biomass loading from 2 to $50 \mathrm{wt} \%$ showed a steady increase in pulp yields from 51 to $63 \%$, while lignin yields decreased from quantitative recovery at $2 \mathrm{wt} \%$ loading to $48.3 \%$ at $50 \mathrm{wt} \%$ loading (Fig. 1). Similarly, delignification and saccharification yield decreased gradually from $86 \%$ and $77 \%$, respectively, to $47 \%$ and $23 \%$ in the same range. The total amount of lignin present in the pulp has been linked to lower saccharification yields. ${ }^{49}$ Some protic ILs can dissolve up to $70 \mathrm{wt} \%$ lignin, ${ }^{50}$ making saturation unlikely, but the addition of ethanol can precipitate large fragments of lignin during the pulp wash. ${ }^{51}$ Therefore, the decrease in lignin yields and delignification combined with the increase in pulp yields may be due to precipitation of lignin during the ethanol washing step, an idea reinforced by the results of the experiments with DMSO washing (see below). At higher loadings, the higher concentrations of dissolved lignin resulted in a greater amount of re-precipitation upon anti-solvent addition. This may influence the initial hydrolysis rate, as redeposited lignin hinders the accessible surface area of the pulp for the enzymes. Therefore, the kinetics of the enzymatic hydrolysis over a 7-day period of the pulps was investigated, including the initial hydrolysis rate (glucose released in the first $2 \mathrm{~h}$ ) and the biomass digestibility after 7 days (Figure ESI-3, Table 1).

The initial hydrolysis rate decreased from 6.1 to $1.5 \%$ glucose $\cdot \mathrm{h}^{-1}$ when the loading was increased from 2 to $50 \mathrm{wt} \%$. This may be related to the enzyme-accessible surface area of biomass, indicating a greater amount of re-precipitated lignin on the pulp surface, which hinders enzyme access to cellulose. ${ }^{52,53}$ Final glucose yields after 7 days of enzymatic hydrolysis also decreased with biomass loading, attributed to higher residual lignin content of the pulp. ${ }^{16}$ If the glucan yield is normalized to the glucan present in the pulp, rather than glucan in untreated biomass, at $2 \mathrm{wt} \%$ loading the pulp glucan was nearly quantitatively hydrolyzed but at $50 \mathrm{wt} \%$ loading only $27 \%$ was, presumably due to lignin re-precipitation (Table 1 ). Similar results were obtained with [Emim][OAc] pretreatments, which found decreased saccharification kinetics and final biomass digestibility at $50 \mathrm{wt} \%$ loading compared to $10 \mathrm{wt} \% .{ }^{10}$ However, for cellulose- 
dissolving ILs the possibility of lignin re-precipitation onto the pulp surface is limited and the negative effect of loading on saccharification was lower.

Table 1

Initial glucose release after $\mathbf{2} \mathrm{h}$ and final glucose release after 7 days of hydrolysis.

\begin{tabular}{|llll|}
\hline & $\begin{array}{l}\text { Initial hydrolysis } \\
\text { rate }\left(\% \mathbf{h}^{-1}\right)^{\mathbf{a}}\end{array}$ & $\begin{array}{l}7 \text { day glucose yield (wt\% glucan } \\
\text { in untreated biomass) }\end{array}$ & $\begin{array}{l}\text { 7 day glucose yield (wt\% } \\
\text { glucan in biomass pulp) }\end{array}$ \\
\hline $\begin{array}{l}\text { Untreated } \\
\text { Miscanthus }\end{array}$ & $0.7 \pm 0.1$ & $12.2 \pm 0.8$ & $12.2 \pm 0.8$ \\
\hline $2 \%$ loading & $6.1 \pm 0.7$ & $77.3 \pm 3.6$ & $93.3 \pm 5.1$ \\
\hline $5 \%$ loading & $5.3 \pm 0.1$ & $73.3 \pm 3.8$ & - \\
\hline $\begin{array}{l}\text { 10\% } \\
\text { loading }\end{array}$ & $5.2 \pm 0.3$ & $68.3 \pm 1.1$ & $78.4 \pm 4.3$ \\
\hline $\begin{array}{l}20 \% \\
\text { loading }\end{array}$ & $3.7 \pm 0.2$ & $49.6 \pm 1.5$ & $60.1 \pm 1.8$ \\
\hline $\begin{array}{l}30 \% \\
\text { loading }\end{array}$ & $2.8 \pm 0.2$ & $45.4 \pm 1.7$ & - \\
\hline $\begin{array}{l}40 \% \\
\text { loading }\end{array}$ & $2.3 \pm 0.4$ & $34.5 \pm 1.7$ & - \\
\hline $\begin{array}{l}50 \% \\
\text { loading }\end{array}$ & $1.5 \pm 0.3$ & $23.1 \pm 0.5$ & $26.5 \pm 0.6$ \\
\hline
\end{tabular}

a Initial hydrolysis rate determined as glucose released after first $2 \mathrm{~h}$ of hydrolysis.

$b, c$ Final glucose release after 7 day is expressed as two different percentages of glucose release: $b$ ) relative to untreated biomass, and c) relative to pretreated pulp.

\section{Lignin analysis}

The molecular weights $\left(\mathrm{M}_{\mathrm{W}}\right)$ of the precipitated lignins were analyzed by GPC, while changes in interunit linkage and subunit abundance were analyzed by HSQC NMR. HSQC NMR of the recovered lignins suggest a slight trend towards greater ether cleavage with increasing solids loading (Figure ESI-4a). At higher loadings, signal intensities of the $S, G_{2}$ and $G_{6}$ positions appear to have decreased, while that of $S_{\text {cond }}$ and $G_{\text {cond }}$ increased slightly, indicating condensation reactions in $G$ and $S$ units. These differences, however, are not very pronounced. GPC data of the isolated lignins showed a general and gradual decrease in $M_{n}, M_{w}$ and dispersity index $(\Theta)$ with higher loadings (Figure ESI-4b). Similar findings were reported with the PIL $[\mathrm{HBim}]\left[\mathrm{HSO}_{4}\right]$ on the softwood pine. ${ }^{54}$ This could be due to the method used to recover lignin, rather than the effect of higher loading. As previously stated, the addition of ethanol can precipitate larger lignin fragments during the pulp wash. This would become more pronounced at higher concentrations, where the cut-off for the precipitation of larger fragments would lie at lower $\mathrm{M}_{\mathrm{W}} \cdot{ }^{51} \mathrm{It}$ would lead to an apparent trend for increased ether cleavage without more pronounced condensation at 
higher loadings, while increasing pulp yield and decreasing lignin recovery. These results suggest that lignin structure is not significantly altered by use of high solids loadings; however, they show the need for an adapted washing protocol to either avoid re-precipitation or remove re-precipitated lignin from the pulp surface.

\section{IL recovery}

Thermal stability is a key property for IL recycling. [TEA] $\left[\mathrm{HSO}_{4}\right]$ was found to be thermally stable within the detection limits of ${ }^{1} \mathrm{H}$ and ${ }^{13} \mathrm{C}$ NMR at $150{ }^{\circ} \mathrm{C}$ for 100 hours (Figure ESI-8). Hence, IL recyclability is expected to be dependent on IL recovery methods rather than its thermal degradation. The IL liquors produced after pretreatment at various biomass loadings were recovered after lignin precipitation, dried and weighed. IL recoveries approached $99 \mathrm{wt} \%$ for solid loadings of 10 and $20 \mathrm{wt} \%$ but increasing biomass loading led to decreasing IL recovery (Figure ESI-9). Brandt et al. had shown that IL molecules may remain adsorbed or covalently bonded to precipitated lignin. ${ }^{44}$ Therefore, it was thought that the decreasing recovery of IL at higher biomass loadings could be due to a larger quantity of IL being trapped or bound within the lignin macromolecule. However, in this case lower content of $\mathrm{N}$ and $\mathrm{S}$ from the IL was found on the lignins isolated from higher loading fractions (see the mass balance in Fig. 2 below). Hence, the observed "trend" may be due to solvent volumes being halved (from $10 \mathrm{~mL}$ to $5 \mathrm{~mL}$ ) for experiments at high loadings in order to fit large quantities of biomass into $15 \mathrm{~mL}$ tubes. Moreover, $\mathrm{IL}$ recoveries in this setup are likely to be limited by the small quantities of solvent used and should improve upon process scale-up, where small losses as IL sticking to glassware would account for a lower proportion of total IL.

Additionally, the $\mathrm{pH}$ values of a $1 \mathrm{wt} \%$ solution of fresh IL and IL liquors after use at various loadings were recorded and compared (Figure ESI-10) and the proton concentration in undiluted IL solutions was estimated (Table ESI-2). [ $\left.\mathrm{H}^{+}\right]$for the fresh IL was $0.22 \mathrm{mmol} / \mathrm{g}$, while for recovered ILs $\left[\mathrm{H}^{+}\right]$ranged between $0.18-0.20 \mathrm{mmol} / \mathrm{g}$. Decreasing concentration of protons in the liquor with increasing biomass loading was also observed. After pretreatment at 10 and $50 \mathrm{wt} \%$ loading, 11 and $26 \mathrm{~mol} \%$ protons were lost compared to the fresh IL solution, respectively. ${ }^{3}$ This agrees with previous findings that observed a $9 \mathrm{~mol} \%$ decrease in proton concentration after four uses of the IL at $10 \mathrm{wt} \%$ loading. ${ }^{3}$ This suggests that the acidity of the IL solution may need to be adjusted during repeated use, and that the "IL make-up stream" will predominantly consist of sulfuric acid, the far less expensive IL component. ${ }^{3}$

\section{Mass balance}

The elemental compositions of the inputs (Miscanthus and fresh IL) and outputs (pretreated pulps, lignin and recovered IL) were used to determine the mass balance of the process. The total component mass balances for two experiments, conducted at $10 \mathrm{wt} \%$ and $50 \mathrm{wt} \%$ biomass loadings, are displayed in Fig. and the elemental mass balances are shown in Table ESI-3.

These calculations were prompted by the observation of decreasing IL recovery from 99-92\% when loading was increased from $10 \mathrm{wt} \%$ to $50 \mathrm{wt} \%$ (Figure ESI-9). If the missing IL portion were trapped in the lignin matrix, it should then be detected in the $\mathrm{N}$ and $\mathrm{S}$ contents of the lignins. The elemental balance 
(Table ESI-3) shows that $\mathrm{N}$ and $\mathrm{S}$ content and total mass in the lignin was actually lower at higher loading, with residual IL contents of 4.2 and $3.9 \mathrm{wt} \%$ at loadings of 10 and $50 \mathrm{wt} \%$, respectively, and did not account for the difference in IL recovery observed. Lower IL recovery was attributed to the lower total solvent volume used, so minor spillages or other losses accounted for a larger proportion of total mass. The mass recovery decreased from $10 \mathrm{wt} \%$ loading ( $96 \mathrm{wt} \%$ recovery, $4 \% \mathrm{wt}$ loss) to $50 \mathrm{wt} \%$ loading (84 wt\% recovery, $16 \mathrm{wt} \%$ loss). If IL recoveries are set to $100 \%$ (Table ESI-3), total mass losses of $3.3 \mathrm{wt} \%$ and $11.0 \mathrm{wt} \%$ at low and high loadings, respectively, are obtained. This is attributed to evaporation of volatile hemicellulose degradation products (acetic acid, formic acid, furfural and 5-HMF) from the liquor during concentration of the ethanol-IL washes and the removal of the water added during precipitation. It matches well with previous studies that found $3.8 \mathrm{wt} \%$ lost in this form during processing at $10 \mathrm{wt} \%$ loading. ${ }^{3,54}$ Even though a higher system mass was lost at higher loadings, the proportion of mass loss was slightly lower at higher than at lower loadings ( $287 \mathrm{mg} / \mathrm{g}$ vs $297 \mathrm{mg} / \mathrm{g})$, suggesting the mass balance improved at higher biomass loadings.

\section{Effect of pulp washing}

To maintain satisfactory saccharification yields at high solids loadings, the pulps were washed with DMSO after the ethanol wash. DMSO was selected as it is capable of dissolving re-precipitated lignin from the pulps surfaces, is inexpensive $(\sim 1 / \mathrm{kg})^{55}$ and fairly non-toxic. After incubation in DMSO overnight the solvent turned brown, suggesting lignin dissolution, and the pulps became lighter in color (Figure ESI-11). This effect was more pronounced for pulps pretreated at higher loadings, with more reprecipitated lignin. Enzymatic digestibility of the pulps was significantly enhanced. $47-58 \%$ glucose yields were obtained, a relative increase of $28-140 \%$ compared with ethanol-washed pulps (Fig. 3). DMSO washing was more effective for pulps produced at higher loadings. However, glucose yields still decreased with increasing loading, suggesting either that re-precipitated lignin may not be the only factor limiting pretreatment efficacy at higher loadings, or that DMSO washing alone was insufficient to remove all lignin from the pulp surface. On the other hand, DMSO is a non-volatile solvent which would be highly energy-intensive to separate from the IL, which is undesirable for industrial processes as it can increase the operational costs. Other solvents, such as recycled IL, are currently being investigated as alternative washing solvents.

\section{Effect of hornification}

Pulp hornification upon air-drying can reduce enzymatic digestibility. ${ }^{56}$ In industrial processes pulps would be enzymatically hydrolyzed in a wet state, so avoiding hornification is preferable to adding a DMSO-washing step. Therefore, pulps pretreated at $50 \mathrm{wt} \%$ loading were saccharified on a wet basis, which increased the glucose yield by $70 \%$, releasing $66 \mathrm{wt} \%$ of glucose (Figure ESI-14). Yields were further improved to $74 \%$ with addition of a DMSO washing step before saccharification of the wet pulp.

\section{Effect of particle size}


Comminution is highly energy-intensive and costly. Pretreating larger particles would reduce energy costs during biomass processing. ${ }^{23}$ The particle size has a direct effect on the contact and diffusion of chemicals into the complex interior of the lignocellulose structure. ${ }^{32}$ To evaluate the effect of particle size on pretreatment, three different particle size fractions (coarse, medium and fine) of Miscanthus $\times$ giganteus were investigated at $20 \mathrm{wt} \%$ loading (Table 2). Pretreatment with dilute acid $\left(3 \mathrm{wt} \% \mathrm{H}_{2} \mathrm{SO}_{4}\right.$, $120^{\circ} \mathrm{C}, 1.5 \mathrm{~h}$ ) was also compared..$^{57}$

Table 2

Particle size fractions for pretreatment of Miscanthus $\times$ giganteus after comminution by hammer milling. ${ }^{58-60}$

\begin{tabular}{|ll|}
\hline Particle size fraction & Description (Miscanthus) \\
\hline Coarse & $\cdot$ Cylindrical chips with dimension $\sim 3 \times 1 \times 1 \mathrm{~cm}$ \\
& $\cdot$ Size reduction by manual chopping \\
\hline Medium & $\cdot$ Fibers with dimension $\sim 3 \times 0.02 \times 0.01 \mathrm{~cm}$ \\
& $\cdot$ Size reduction by manual chopping \\
\hline Fine & $\cdot 0.18-0.85 \mathrm{~mm}$ (standard size for previous experiments) \\
& $\cdot$ Size reduction by cutting mill $(2 \mathrm{~mm}$ sieve opening size) and sieving \\
\hline
\end{tabular}

Chemical pretreatments, including ionoSolv, soften biomass structure by partially removing and modifying lignin and hemicellulose reducing the particle size. ${ }^{21,61}$ They are able to reduce size down to a certain "boundary", which may be linked to the diameter of cellulose microfibril bundles released during hemicellulose and lignin solubilization. ${ }^{62}$ Fiberization is reflected in the pulp images for Miscanthus, which had similar features regardless of initial particle size (Fig. 4).

The efficacy of pretreating different particle size fractions was evaluated by comparing the pulp and lignin recoveries, pulp delignification, glucose yields released by saccharification, and particle size distribution (PSD) of the pulps. While the enzyme-accessible surface area of the pulp is of most interest for explaining saccharification yields, its measurement is far more complicated than sieving, which was used as the preferred method to assess PSD changes in this study. ${ }^{34}$ Miscanthus pulps were size-reduced during pretreatment (30-68\%, based on the $D_{50}$ values), due to its low recalcitrance and density (Figure ESI-15) ${ }^{63}$ Greater size reduction was observed for larger particles, though the change in $D_{50}$ for the largest size fraction could not be quantified (Table 3). The medium and fine fractions were also pretreated using dilute sulfuric acid $\left(3 \mathrm{wt} \%, 120^{\circ} \mathrm{C}, 1.5\right.$ hours). The recovered pulps closely resembled the starting materials and $D_{50}$ values showed low size reduction for medium particles and virtually none for fine particles (Table 3, Figure ESI-16). IonoSolv pretreatment resulted in a dramatic degree of particle size reduction compared with dilute acid treatment, with a more visible effect for the coarse chips (Fig. 4). For low density grassy biomass feedstocks, it may be possible to use pretreatment for initial size reduction 
followed by post-pretreatment size reduction to produce the fine particles needed for efficient hydrolysis and fermentation, ${ }^{34}$ with added energy reduction due to the presence of the ionic liquid. ${ }^{64}$

Table 3

$D_{50}$ values obtained for untreated biomass and recovered pulps after IL and DA pretreatments.

\begin{tabular}{|llll|}
\hline $\begin{array}{l}\text { Geometric mean average diameter } D_{50} \\
(\mathbf{m m})\end{array}$ & $\begin{array}{l}\text { Coarse } \\
\text { pulp }\end{array}$ & Medium pulp & Fine pulp \\
\hline Miscanthus Untreated & - & $1.9 \pm 0.1$ & $0.37 \pm 0.02$ \\
\hline Miscanthus ionoSolv & $1.0 \pm 0.2(-)$ & $\begin{array}{l}0.61 \pm 0.01(- \\
68 \%)\end{array}$ & $\begin{array}{l}0.26 \pm 0.01(- \\
30 \%)\end{array}$ \\
\hline Miscanthus DA & - & $1.7 \pm 0.0(-11 \%)$ & $0.4 \pm 0.02(\sim 0 \%)$ \\
\hline
\end{tabular}

Particle size distributions were obtained by sieving. Values in brackets denote the percentage change in $D_{50}$ values of the treated pulp based on the original untreated feedstock.

Glucose yields were determined after grinding and sieving all pretreated pulps to $0.18-0.85 \mathrm{~mm}$. No significant difference was seen in the glucan recovery values for coarse and medium particles (all 90\%), while a slightly greater degree of glucan loss was noted for fine particles (Fig. 5). This, previously observed for rice straw pretreatment, ${ }^{32}$ suggests excess acidity in the IL, ${ }^{43}$ which would have a greater effect for fine particles, with higher volumetric surface area exposed to the $\mathrm{H}^{+}$protons. Hemicellulose extraction was more effective for finer particles due to greater sugar accessibility. Delignification showed a different trend, being greatest (60\%) for medium particles. Coarse particles were less delignified due to the lower surface area to volume ratio; while fine particles also showed lower delignification than expected, presumedly due to re-precipitation of lignin onto the large pulp surface area. The lignin recovery, which was highest for fine particles, provides further evidence; though delignification was limited due to re-precipitation of lignin onto the pulp surface. As a result, saccharification yields were higher for medium $(77 \%)$ than for fine particles (67\%). This suggests that the presence of lignin has a stronger negative effect on glucose yields than the positive effect of hemicellulose removal, as was previously noted. ${ }^{54}$ These saccharification results were obtained for size-reduced pulps, which adds extra energy penalty but may be unnecessary for scale-up studies.

Based on this, the optimum size for unstirred Miscanthus pretreatment appears to be 1-3 $\mathrm{mm}$ long particles, in line with the proposed particle size range of 2-6 $\mathrm{mm}$ recommended by Cadoche and López to minimize comminution energy. ${ }^{19}$

Dilute acid treatment removed the majority of hemicellulose and small amounts of lignin (Figure ESI-18), as reported in literature. ${ }^{65,66}$ However, delignification $(\sim 10 \%)$ and glucose yields ( 28\%) were very low for all size fractions. IonoSolv pretreatment offers many advantages over dilute acid pretreatment such as greater reduction in particle size, higher volumetric surface areas of the pulps, lower lignin contents, and higher lignin recoveries. 


\section{Effect of 100-fold scale-up}

Here, we demonstrate the 100-fold scale-up of the ionoSolv deconstruction of Miscanthus, relative to the bench scale $(1 \mathrm{~L}$ vs $0.01 \mathrm{~L})$ under the same conditions $\left(120^{\circ} \mathrm{C}, 6 \mathrm{~h}\right)$ and with solid loadings between $10-$ $20 \mathrm{wt} \%$ (> $20 \mathrm{wt} \%$ could not be attempted due to stirrer motor limitations), using different particle sizes and stirring speeds. Insights into the effect of scale-up were garnered by comparing pulp and lignin recoveries, pulp composition and saccharification and lignin characteristics.

\section{Pulp washing protocol optimization}

The volume of solvent employed for pulp washing at the bench scale becomes impractical at larger scales. Material handling and pulp washing at larger scales is a critical operation that requires improvement. ${ }^{35}$ Three methods were investigated to adapt the protocol for $\sim 100 \mathrm{~g}$ of pulp: muslin cloth straining, centrifugation and vacuum filtration. Each washing step used $1 \mathrm{~mL}$ of ethanol per $\mathrm{g}$ of IL. Multiple washing steps with smaller volumes each should lead to better IL removal from the pulp with lower solvent requirements, as the constant partition coefficient for IL between the wash solvent and pulp is multiplied geometrically over multiple cycles. To assess this, the IL content in the solid fraction was measured to track the efficiency of washing steps, and the pulp samples were subjected to saccharification to evaluate the degree of inhibition by residual IL (Figure ESI-12).

Straining using a muslin cloth rapidly reduced IL content, giving acceptable digestibility after only 4 washes. However, further washing could not reduce the pulp IL content to below $6 \%$, which could be problematic for downstream processing. Centrifugation required up to 16 washing steps to reduce the IL content to $8 \%$, glucose yields were slow to increase and the pulps appeared clumpy and compressed (Figure ESI-13), which may limit washing efficacy. Vacuum filtration was the most effective, producing fluffy pulp that gave high glucose yields after only 6 washes. A steady decrease in IL content to $4 \%$ after 8 washes and $<0.5 \%$ after 12 washes was noted. Vacuum filtration with 10 washing steps was found optimal, giving high glucose digestibility, saving 25\% ethanol compared to bench scale and eliminating the need for a Soxhlet extraction step.

\section{Product recoveries and pretreatment effectiveness}

Pulp yield recoveries for finely ground Miscanthus at $10 \mathrm{wt} \%$ and $20 \mathrm{wt} \%$ loadings ( $49.7 \%$ and $52.7 \%$, respectively, Fig. 6-a) were slightly lower than at the $10 \mathrm{~mL}$ scale $(51.6 \%$ and $52.9 \%)$. Higher lignin precipitate yields, slightly higher delignification, hemicellulose removal, glucan recovery and improved glucose release were also seen at the $1 \mathrm{~L}$ scale, except for the hemicellulose extraction at $20 \mathrm{wt} \%$ loading (Fig. 6-a, Table 4). These effects were attributed to improved heat and mass transfer upon the introduction of stirring.

At the $1 \mathrm{~L}$ scale, higher solids concentrations (20 wt\% loading) increased the surface area for lignin reprecipitation onto the pulp, resulting in lower delignification, lignin and saccharification yields. However, this decrease in delignification and saccharification yield at $20 \%$ loading at the $1 \mathrm{~L}$ scale $(9 \%$ and $16 \%$ 
lower, respectively) was less significant than at $10 \mathrm{~mL}$ scale (11\% and $19 \%$ lower, respectively). Quantitative IL liquor recovery was also obtained.

The effect of different particle sizes was also compared for both scales. More pronounced differences were found in product yields upon scale-up with increasing particle size (Fig. 6-b, Table 4). The decrease in pulp yield upon up-scaling was subtle for fine particles $(2 \%$ decrease at the $1 \mathrm{~L}$ compared to the $10 \mathrm{~mL}$ scale), whereas for medium and coarse fractions it was more pronounced (around 10\% drop, in both cases). Lower pulp yields can be explained by improved lignin and hemicellulose extraction, as evidenced by compositional analysis. Stirred scale-up experiments also gave higher lignin precipitate yields, particularly for larger particle sizes.

All the pulps were subjected to saccharification without further size reduction (Table 5). Glucose yields for fine particles (80\%) compared closely to those from $10 \mathrm{~mL}$ scale (79\%). For medium particles a slight increase in glucose yield was found ( $68 \%$ vs $66 \%$ ). Tellingly, the more drastic improvement was seen for coarse pulps ( $59 \%$ vs $45 \%$ ), likely due to the improved mass transfer and size reduction during pretreatment with stirring. High uncertainty $(\sim 18 \%$ error) in the glucose yield for coarse particles was attributed to particle size heterogeneity. IL liquor recoveries were improved at the $1 \mathrm{~L}$ scale due to larger solvent volumes used; recoveries exceeding $100 \mathrm{wt} \%$ are due to lignin fragments and other non-volatile extractives remaining in the liquor. 
Table 4

Key pretreatment outcomes at $10 \mathrm{~mL}$ vs $1 \mathrm{~L}$ scale as a function of particle size.

\begin{tabular}{|c|c|c|c|c|}
\hline & $\begin{array}{l}\text { Delignification } \\
\text { (wt\%) a }\end{array}$ & $\begin{array}{l}\text { Lignin mass } \\
\text { balance (wt\%) }\end{array}$ & $\begin{array}{l}\text { Saccharification } \\
\text { yield }^{\mathrm{C}}(\%)\end{array}$ & $\begin{array}{l}\text { IL liquor } \\
\text { recovery (wt\%) }\end{array}$ \\
\hline $\begin{array}{l}10 \mathrm{~mL}-\text { fine }-10 \% \\
\text { loading }\end{array}$ & $85 \pm 4$ & $99 \pm 6$ & $79.9 \pm 0.4$ & $98.7 \pm 0.6$ \\
\hline $\begin{array}{l}1 \mathrm{~L}-\text { fine }-10 \% \\
\text { loading }\end{array}$ & $87 \pm 2$ & $102 \pm 6$ & $79.1 \pm 0.5$ & $100.5 \pm 0.6$ \\
\hline $10 \mathrm{~mL}-20 \%$ loading & $74 \pm 6$ & $106 \pm 7$ & $60.8 \pm 3.4$ & $98.3 \pm 0.4$ \\
\hline $\begin{array}{l}1 \mathrm{~L}-\text { fine }-20 \% \\
\text { loading }\end{array}$ & $78 \pm 3$ & $104 \pm 7$ & $63.2 \pm 2.7$ & $103.1 \pm 0.3$ \\
\hline $\begin{array}{l}10 \mathrm{~mL}-\text { medium - } \\
10 \% \text { loading }\end{array}$ & $82 \pm 4$ & $77 \pm 7$ & $66.3 \pm 6.5$ & $101.6 \pm 2.7$ \\
\hline $1 \mathrm{~L}-$ medium $-10 \%$ & $83 \pm 4$ & $93 \pm 4$ & $68.2 \pm 4.8$ & $100.9 \pm 0.2$ \\
\hline $\begin{array}{l}10 \mathrm{~mL} \text { - coarse - } \\
10 \%\end{array}$ & $56 \pm 6$ & $77 \pm 16$ & $45.0 \pm 3.6$ & $99.9 \pm 0.5$ \\
\hline $1 \mathrm{~L}-$ coarse $-10 \%$ & $69 \pm 4$ & $95 \pm 5$ & $59.3 \pm 10.5$ & $101.8 \pm 0.6$ \\
\hline \multicolumn{5}{|c|}{$\begin{array}{l}\text { a Based on feedstock lignin content (AIL + ASL), as determined by compositional analysis of } \\
\text { untreated Miscanthus. }\end{array}$} \\
\hline \multicolumn{5}{|c|}{ b Sum of residual lignin in pulp and isolated lignin yield. } \\
\hline
\end{tabular}

\section{Insights from lignin HSQC NMR and GPC}

The lignin precipitates obtained from stirred scale-up experiments for different loadings and particle sizes were analysed by HSQC NMR and GPC. When increasing loading from $10 \mathrm{wt} \%$ to $20 \mathrm{wt} \%$ at $1 \mathrm{~L}$ scale, precipitated lignins showed similar ether cleavage and condensation, as observed by levels of $\beta$-aryl ether, $\mathrm{G}_{2}$ and $\mathrm{G}_{2 \text {,cond }}$ sub-units (Figure ESI-6). Different feedstock particle sizes, however, resulted in lignin with more distinct properties. For the largest particle sizes with lower volumetric surface area, IL diffusion into the particles and lignin diffusion out of the particles is slower, with lower proton/IL concentration at the particle core, reducing the rate of lignin extraction from the core and producing less depolymerized and less condensed lignins. This was seen from increasing $\beta-0-4$ ' linkage abundance, increase in $S$ and decrease in $S_{\text {cond }}$ sub-units, and increase in S/G ratio as determined by HSQC NMR analysis of lignins extracted from coarse Miscanthus chips.

The precipitated lignins also had higher $M_{w}$ for coarse (6500) than for fine particles (4900, Table 5). The increase in $€$ values with particle size (from 4.1 to 5.3 ) could be explained by less depolymerized lignins 
being released from the core while smaller lignins still being released from the surface of the particles. $\boxplus$ values were also higher than at the bench scale (2.7-3.0). These differences highlight the improvement in ionoSolv processing upon scale-up with stirring. Better mass transfer due to mixing may facilitate extraction and dispersion of lignin fragments in the IL.

Table 5

Lignin characteristics at the $1 \mathrm{~L}$ scale as a function of solid loading and particle size.

\begin{tabular}{|lllll|}
\hline & S/G ratio $(-)$ & $\mathbf{M}_{\mathbf{w}}(\mathbf{g} / \mathbf{m o l})$ & $\oplus(-)$ & $\beta-O-4^{\prime}$ abundance \\
\hline Fine $-10 \%$ & 0.70 & 4900 & 4.1 & 20.3 \\
\hline Fine $-20 \%$ & 0.72 & 5000 & 4.1 & 17.7 \\
\hline Medium $-10 \%$ & 0.69 & 5760 & 4.4 & 19.5 \\
\hline Coarse $-10 \%$ & 0.79 & 6500 & 5.3 & 24.8 \\
\hline
\end{tabular}

\section{Effect of stirring}

The power requirements of mixing are non-negligible and demand optimization of slurry density and viscosity, mixing velocity and agitator design. ${ }^{2}$ An anchor agitator design was selected, after testing different designs, as the most effective for mixing IL-biomass slurries. The effect of stirring speed on pretreatment was assessed by comparing stirring at $150 \mathrm{rpm}$ and the maximum possible speed for a given slurry at $10 \mathrm{wt} \%$ loading (450 rpm for fine particles, $250 \mathrm{rpm}$ for the medium particles and $400 \mathrm{rpm}$ for coarse chips). Despite different 'maximal' stirring speeds, the amount of energy delivered per second to the IL-biomass slurry upon an increase in mixing speed was the same (i.e. the maximum stirrer power).

Increasing stirring speed resulted in slightly lower pulp yield and higher lignin precipitate yield, suggesting improved lignin extraction (Fig. 6-C). This became more prominent with increasing particle size. However, pulp compositions were not significantly affected. Increasing the stirring speed did not significantly affect saccharification yields with the exception of the fine fraction, which dropped drastically upon increasing stirring speed from 150 to $450 \mathrm{rpm}$ (from 79.1-66.1\%, Table 7).

More rapid lignin extraction may take place with greater mixing due to improved heat and mass transfer. However, as fine particles have higher volumetric surface area, this increases the available pulp surface for lignin re-precipitation, worsened by particle size reduction during pretreatment. Consequently, overall delignification remained approximately constant with stirring speed (Table 7). However, for the coarse particle size fraction, increasing the stirring speed from 150 to $400 \mathrm{rpm}$ improved delignification (from $69-87 \%)$ though glucose yields were very similar (59\%). This indicates that mixing speed should be optimized depending on the particle size of the feedstock. The use of high stirring speeds at elevated temperatures for short residence times could help to maximize delignification and avoid prolonged contact of the pulp with the liquor to reduce lignin re-precipitation. 
Table 7

Key pretreatment outcomes at $10 \mathrm{~mL}$ vs $1 \mathrm{~L}$ scale as a function of stirring speed. ${ }^{a}$

\begin{tabular}{|lllll|}
\hline & $\begin{array}{l}\text { Delignification } \\
(w t \%)\end{array}$ & $\begin{array}{l}\text { Lignin mass } \\
\text { balance }(w t \%)\end{array}$ & $\begin{array}{l}\text { Saccharification } \\
\text { yield (\%) }\end{array}$ & $\begin{array}{l}\text { IL liquor recovery } \\
(w t \%)\end{array}$ \\
\hline $\begin{array}{l}\text { Fine }- \\
150 \mathrm{rpm}\end{array}$ & $87 \pm 2$ & $102 \pm 6$ & $79.1 \pm 0.5$ & $100.5 \pm 0.6$ \\
\hline $\begin{array}{l}\text { Fine - } \\
450 \mathrm{rpm}\end{array}$ & $88 \pm 2$ & $101 \pm 2$ & $66.1 \pm 4.6$ & $99.2 \pm 0.6$ \\
\hline $\begin{array}{l}\text { Medium }- \\
150 \mathrm{rpm}\end{array}$ & $83 \pm 4$ & $93 \pm 4$ & $68.2 \pm 4.8$ & $100.9 \pm 0.2$ \\
\hline $\begin{array}{l}\text { Medium }- \\
250 \mathrm{rpm}\end{array}$ & $83 \pm 6$ & $93 \pm 6$ & $67.8 \pm 3.0$ & $102.0 \pm 0.2$ \\
\hline $\begin{array}{l}\text { Coarse }- \\
150 \mathrm{rpm}\end{array}$ & $69 \pm 4$ & $95 \pm 5$ & $59.3 \pm 10.5$ & $101.8 \pm 0.6$ \\
\hline $\begin{array}{l}\text { Coarse }- \\
400 \mathrm{rpm}\end{array}$ & $87 \pm 2$ & $102 \pm 3$ & $59.0 \pm 7.4$ & $100.7 \pm 0.6$ \\
\hline
\end{tabular}

a Selected stirring speeds: $150 \mathrm{rpm}$ and maximal stirring speed that can be achieved for a particular experiment (250-450 rpm).

$D_{50}$ values showed that faster mixing gave rise to greater in situ size reduction, producing pulps with lower average particle size and hence higher volumetric surface area (Figure ESI-17). $D_{50}$ values after pretreatment showed a greater decrease than for unstirred experiments at the bench scale $(40,91$ and $96 \%$ for fine, medium and coarse particles vs 30 and $68 \%$ for fine and medium particles at bench scale).

The lignin precipitates recovered from $1 \mathrm{~L}$ scale experiments at different mixing speeds were analyzed by HSQC NMR and GPC. Only subtle differences in lignin characteristics were observed (Figure ESI-5). In all cases, faster mixing speeds produced lignins with a slightly lower abundance of $\beta-0-4$ ' ether linkages, suggesting it is more cleaved. Also, a slight increase in signal intensity for $G_{6}$ units, lower amounts of $G_{2}$ and higher $G_{2, \text { cond }}$ subunits were seen, suggest that lignins extracted using faster mixing were also more condensed. The implication, based on analysis of the lignin yields and structure, is that faster mixing led to a transition from "diffusion controlled" to "kinetically controlled" reaction regimes, leading to more condensation.

GPC analysis of the lignins (Table ESI-4) showed that increasing mixing speeds produced lignin precipitates with lower molecular weight, which may be due to a greater likelihood of lignin macromolecules precipitating onto the (increased) pulp surface area, though this is unclear. The different results in lignin yield, delignification and $\mathrm{M}_{\mathrm{W}}$ depending on particle size illustrate the combined effects of lignin reactivity (producing more condensed lignins) and lignin re-precipitation (reducing the proportion of high $\mathrm{M}_{\mathrm{W}}$ lignins remaining in solution until the water addition step), both of which appear to become enhanced with stirring speeds. 


\section{Conclusions}

Process intensification of the ionoSolv process using the low-cost PIL [TEA][HSO $\left.{ }_{4}\right]$ and the grassy biomass Miscanthus was investigated, including the effects of biomass loading, particle size, 100-fold scaling up and stirring speed.

Glucose yields for Miscanthus decreased from 68-23\% upon five-fold increase in loading from 10 to $50 \mathrm{wt} \%$, at the $10 \mathrm{~mL}$ scale, which arose due to re-precipitation of the extracted lignin onto the pulp surface under higher lignin concentrations. Saccharification yields were maintained at $66 \%$ by omitting the air-drying step, as saccharifying wet pulps reduced fiber hornification.

The pretreatment of Miscanthus at different particle sizes was investigated. In unstirred conditions, the use of particle sizes of 1-3 $\mathrm{mm}$ was preferable over fine powders $(0.18-0.85 \mathrm{~mm})$, due to reduced surface area available for lignin re-precipitation, giving higher glucose yields while minimizing grinding energy needs. Comparison with dilute acid pretreatment showed ionoSolv processing is far more tolerant to use of larger particle sizes.

100-fold scale-up (from $10 \mathrm{~mL}$ to $1 \mathrm{~L}$ ) improved the efficacy of ionoSolv pretreatment, after optimizing pulp washing protocols and agitator design, due to improved heat and mass transfer with slurry mixing. The introduction of stirring allowed higher delignification, reduced lignin condensation and improved lignin mass balance, particularly for larger particles $(10-12 \mathrm{~mm})$. Doubling of the solid loading at the $1 \mathrm{~L}$ scale from 10 to $20 \mathrm{wt} \%$ showed reduced lignin re-precipitation onto the pulp surface, giving higher glucose yields. IL liquor recovery rates were found to be $>99.2 \%$ in all cases. Substantial cost savings could be realized by tailoring the pre-processing size reduction stages to an individual feedstock. Minimal stirring is preferable to minimize energy requirements.

Stirred ionoSolv pretreatment offers great potential for industrialization and further process intensification by selection of optimum pretreatment conditions (temperature, residence time, stirring speed), particle size and biomass loading depending on the feedstock. Pulp washing protocols need further improvement to reduce both the incidence of lignin precipitation in ethanol and water requirements of lignin washing. Integrating these process parameters into improved process models of the ionoSolv process could enable identification of the remaining bottlenecks to achieve economic viability and estimate the life cycle greenhouse gas savings of scaled-up IL-based biorefining.

\section{Declarations}

\section{Ethics approval and consent to participate}

Not applicable

\section{Consent for publication}




\section{Competing interests}

The authors declare that they have no competing interests

\section{Funding}

The authors wish to acknowledge the Engineering and Physical Sciences Research Council and the Supergen Bioenergy Hub for supporting CC (EP/N509486/1) and PV (EP/S000771/1).

\section{Authors' contributions}

CC carried out all experimental work. PV edited and prepared the manuscript along with $\mathrm{JH}$. All authors read and approved the final manuscript.

\section{Acknowledgements}

We would like to thank Mr Daniel Ogbonna for laboratory assistance.

\section{Availability of data and material}

All data generated or analysed during this study are included in this published article and its supplementary information files. Materials can be made available upon reasonable request to the author.

\section{References}

1 D. Humbird, R. Davis, L. Tao, C. Kinchin, D. Hsu, A. Aden, P. Schoen, J. Lukas, B. Olthof, M. Worley, D. Sexton and D. Dudgeon, Process design and economics for conversion of lignocellulosic biomass to ethanol, 2011, vol. 303.

2 D. Klein-Marcuschamer, B. A. Simmons and H. W. Blanch, Biofuels, Bioprod. Biorefining, 2011, 5, 562569.

3 A. Brandt-Talbot, F. J. V. V. Gschwend, P. S. Fennell, T. M. Lammens, B. Tan, J. Weale and J. P. Hallett, Green Chem., 2017, 19, 3078-3102.

4 A. George, A. Brandt, K. Tran, S. M. S. N. S. Zahari, D. Klein-Marcuschamer, N. Sun, N. Sathitsuksanoh, J. Shi, V. Stavila, R. Parthasarathi, S. Singh, B. M. Holmes, T. Welton, B. A. Simmons and J. P. Hallett, Green Chem., 2015, 17, 1728-1734. 
5 C. L. Chambon, V. Fitriyanti, P. Verdía, S. M. Yang, S. Hérou, M.-M. Titirici, A. Brandt-Talbot, P. S. Fennell and J. P. Hallett, ACS Sustain. Chem. Eng., 2020, 8, 3751-3761.

6 J. Zhang, W. Hou and J. Bao, Adv. Biochem. Eng. Biotechnol., 2015, 152, 75-90.

7 X.-S. Z. Yu Zhang, Yun-Yun Liu, Jing-Liang Xu, Zhen-Hong Yuan, BioResources, 2012, 7, 345-353.

8 I. P. Wood, H. G. Cao, L. Tran, N. Cook, P. Ryden, D. R. Wilson, G. K. Moates, S. R. A. Collins, A. Elliston and K. W. Waldron, Biotechnol. Biofuels, 2016, 9, 1-9.

9 F. J. V. Gschwend, C. L. Chambon, M. Biedka, A. Brandt-Talbot, P. S. Fennell and J. P. Hallett, Green Chem., 2019, 21, 692-703.

10 A. G. Cruz, C. Scullin, C. Mu, G. Cheng, V. Stavila, P. Varanasi and D. Xu, Biotechnol. Biofuels, 2013, 6, $1-9$.

11 S. Viamajala, B. S. Donohoe, S. R. Decker, T. B. Vinzant, M. J. Selig, M. E. Himmer and M. P. Tucker, in Sustainable Biotechnology, ed. O. M. S. and S. P. Harvey, Springer New York, 2010, pp. 1-18.

12 J. R. . Samaniuk, Measurement and Modification of Biomass Rheological Properties, PhD Thesis, University of Wisconsin-Madison, USA, 2012.

13 H. Wu, M. Mora-Pale, J. Miao, T. V. Doherty, R. J. Linhardt and J. S. Dordick, Biotechnol. Bioeng., 2011, 108, 2865-2875.

14 M. J. Selig, S. Viamajala, S. R. Decker, M. P. Tucker, M. E. Himmel and T. B. Vinzant, Biotechnol. Prog., 2007, 23, 1333-1339.

15 H. Li, Y. Pu, R. Kumar, A. J. Ragauskas and C. E. Wyman, Biotechnol. Bioeng., 2014, 111, 485-492.

16 L. Laureano-Perez, F. Teymouri, H. Alizadeh and B. E. Dale, Appl. Biochem. Biotechnol., 2005, 124, 1081-1099.

17 S. J. B. Duff and W. D. Murray, Bioresour. Technol., 1996, 55, 1-33.

18 Y. Sun and J. Cheng, Bioresour. Technol., 2002, 83, 1-11.

19 L. Cadoche and G. D. López, Biol. Wastes, 1989, 30, 153-157.

20 J. J. Jacobson, M. S. Roni, P. Lamers and K. G. Cafferty, Biomass Feedstock Supply System Design and Analysis, 2014.

21 J. Y. Zhu and X. J. Pan, Bioresour. Technol., 2010, 101, 4992-5002.

22 S. Levey, Imp. Coll. London News, 2012, http://www3.imperial.ac.uk/newsandeventspggrp/impe. 
23 S. A. Hosseini and N. Shah, Bioresour. Technol., 2009, 100, 2621-2628.

24 B. C. Vidal, B. S. Dien, K. C. Ting and V. Singh, Appl. Biochem. Biotechnol., 2011, 164, 1405-1421.

$25 \mathrm{E}$. Khullar, Miscanthus conversion to ethanol: effect of particle size and pretreatment conditions for hot water, PhD Thesis, University of Illinois at Urbana-Champaign, USA, 2012.

26 E. Bahcegul, S. Apaydin, I. Haykir, U. Bakir, N. I. Haykir, E. Tatli and U. Bakir, Green Chem., 2012, 14, 1896.

27 W. Li, N. Sun, B. Stoner, X. Jiang, X. Lu and R. D. Rogers, Green Chem., 2011, 13, 2038-2047.

28 J. Sun, T. Dutta, R. Parthasarathi, K. H. Kim, N. Tolic, R. K. Chu, N. G. Isern, J. R. Cort, B. A. Simmons and S. Singh, Green Chem., 2016, 18, 6012-6020.

29 X.-D. Hou, N. Li and M.-H. Zong, ACS Sustain. Chem. Eng., 2013, 1, 519-526.

30 H. Ren, M.-H. Zong, H. Wu and N. Li, Ind. Eng. Chem. Res., 2016, 55, 1788-1795.

31 G. Papa, T. Feldman, K. L. Sale, F. Adani, S. Singh and B. A. Simmons, Bioresour. Technol., 2017, 241, 627-637.

32 T.-A. D. Nguyen, K.-R. Kim, S. J. Han, H. Y. Cho, J. W. Kim, S. M. Park, J. C. Park and S. J. Sim, Bioresour. Technol., 2010, 101, 7432-7438.

33 J. Shi, V. S. Thompson, N. A. Yancey, V. Stavila, B. A. Simmons and S. Singh, Biofuels, 2013, 4, 63-72.

34 W. Zhu, J. Y. Zhu, R. Gleisner and X. J. Pan, Bioresour. Technol., 2010, 101, 2782-2792.

35 C. Li, D. Tanjore, W. He, J. Wong, J. L. Gardner, K. L. Sale, B. A. Simmons and S. Singh, Biotechnol. Biofuels, 2013, 6, 154.

36 F. A. Ferrari, J. F. B. Pereira, G. J. Witkamp and M. B. S. Forte, ACS Sustain. Chem. Eng., 2019, 7, 12779-12788.

37 C. Yu, B. A. Simmons, S. W. Singer, M. P. Thelen and J. S. VanderGheynst, Appl. Microbiol. Biotechnol., $2016,100,10237-10249$.

38 Q. Dickinson, S. Bottoms, L. Hinchman, S. Mcllwain, S. Li, C. L. Myers, C. Boone, J. J. Coon, A. Hebert, T. K. Sato, R. Landick and J. S. Piotrowski, Microb. Cell Fact., 2016, 15, 1-13.

39 C. Li, D. Tanjore, W. He, J. Wong, J. L. Gardner, V. S. Thompson, N. A. Yancey, K. L. Sale, B. A. Simmons and S. Singh, BioEnergy Res., 2015, 8, 982-991.

40 H. Baaqel, I. Díaz, V. Tulus, B. Chachuat, G. Guillén-gosálbez and J. P. Hallett, Green Chem., 2020, 22, 3132-3140. 
41 L. Weigand, S. Mostame, A. Brandt-Talbot, T. Welton, J. P. Hallett, A. Brandt, T. Welton and J. P. Hallett, Faraday Discuss., 2017, 202, 331-349.

42 A. Brandt, F. Gschwend, P. Fennell, T. Lammens, B. Tan, J. Weale and J. Hallett, Green Chem., 2017, 3078-3102.

43 P. Verdía, A. Brandt, J. P. Hallett, M. J. Ray and T. Welton, Green Chem., 2014, 16, 1617-1627.

44 A. Brandt, L. Chen, B. E. van Dongen, T. Welton and J. P. Hallett, Green Chem., 2015, 17, 5019-5034.

45 F. J. V. Gschwend, F. Malaret, S. Shinde, A. Brandt-Talbot and J. P. Hallett, Green Chem., 2018, 20, 3486-3498.

46 F. J. V Gschwend, A. Brandt, C. L. Chambon, W.-C. Tu, L. Weigand and J. P. Hallett, JoVE, 2016, e54246.

47 A. Sluiter, B. Hames, R. Ruiz, C. Scarlata, J. Sluiter, D. Templeton and D. Crocker, Determination of Structural Carbohydrates and Lignin in Biomass, 2004, vol. 2011.

48 M. G. Resch, J. O. Baker and S. R. D. Nrel, Low Solids Enzymatic Saccharification of Lignocellulosic Biomass Low Solids Enzymatic Saccharification of Lignocellulosic Biomass Laboratory Analytical Procedure ( LAP), 2015.

49 A. Berlin, M. Balakshin, N. Gilkes, J. Kadla, V. Maximenko, S. Kubo and J. Saddler, J. Biotechnol., 2006, $125,198-209$.

50 T. Rashid, C. F. Kait, I. Regupathi and T. Murugesan, Ind. Crops Prod., 2016, 84, 284-293.

51 A. Procentese, E. Johnson, V. Orr, A. [Garruto Campanile], J. A. Wood, A. Marzocchella and L. Rehmann, Bioresour. Technol., 2015, 192, 31-36.

52 D. P. Maurya, A. Singla and S. Negi, 3 Biotech, 2015, 5, 597-609.

53 X. Meng and A. J. Ragauskas, Curr. Opin. Biotechnol., 2014, 27, 150-158.

54 F. J. V. Gshwend, Towards an economical ionic liquid based biorefinery, PhD Thesis, Imperial College London, 2017.

55 Alibaba, Alibaba.

56 X. L. Luo, J. Y. Zhu, R. Gleisner and H. Y. Zhan, Cellulose, 2011, 18, 1055-1062.

57 C. Li, L. Sun, B. A. Simmons and S. Singh, Bioenergy Res., 2013, 6, 14-23.

58 L. J. Naimi, F. Collard, X. Bi, C. J. Lim and S. Sokhansanj, Biomass Convers. Biorefinery, 2016, 6, 397405. 
59 Z. Miao, T. E. Grift, A. C. Hansen and K. C. Ting, Ind. Crops Prod., 2011, 33, 504-513.

60 N. A. Yancey, J. S. Tumuluru and C. T. Wright, J. Biobased Mater. Bioenergy, 2013, 7, 549-558.

61 A. Brandt, J. Gräsvik, J. P. Hallett and T. Welton, Green Chem., 2013, 15, 550-583.

62 W. Stelte, Steam explosion for biomass pre-treatment, Danish Technological Institute Report, Center for Renewable Energy \& Transport, 2013.

63 J. Y. Zhu, ACS Symp. Ser., 2011, 1067, 89-107.

64 A. Brandt, J. K. Erickson, J. P. Hallett, R. J. Murphy, A. Potthast, M. J. Ray, T. Rosenau, M. Schrems and T. Welton, Green Chem., 2012, 14, 1079-1085.

65 Y. Pu, F. Hu, F. Huang, B. H. Davison and A. J. Ragauskas, Biotechnol. Biofuels, 2013, 6, 1.

66 C. Li, B. Knierim, C. Manisseri, R. Arora, H. V Scheller, M. Auer, K. P. Vogel, B. A. Simmons and S. Singh, Bioresour. Technol., 2010, 101, 4900-4906.

\section{Figures}

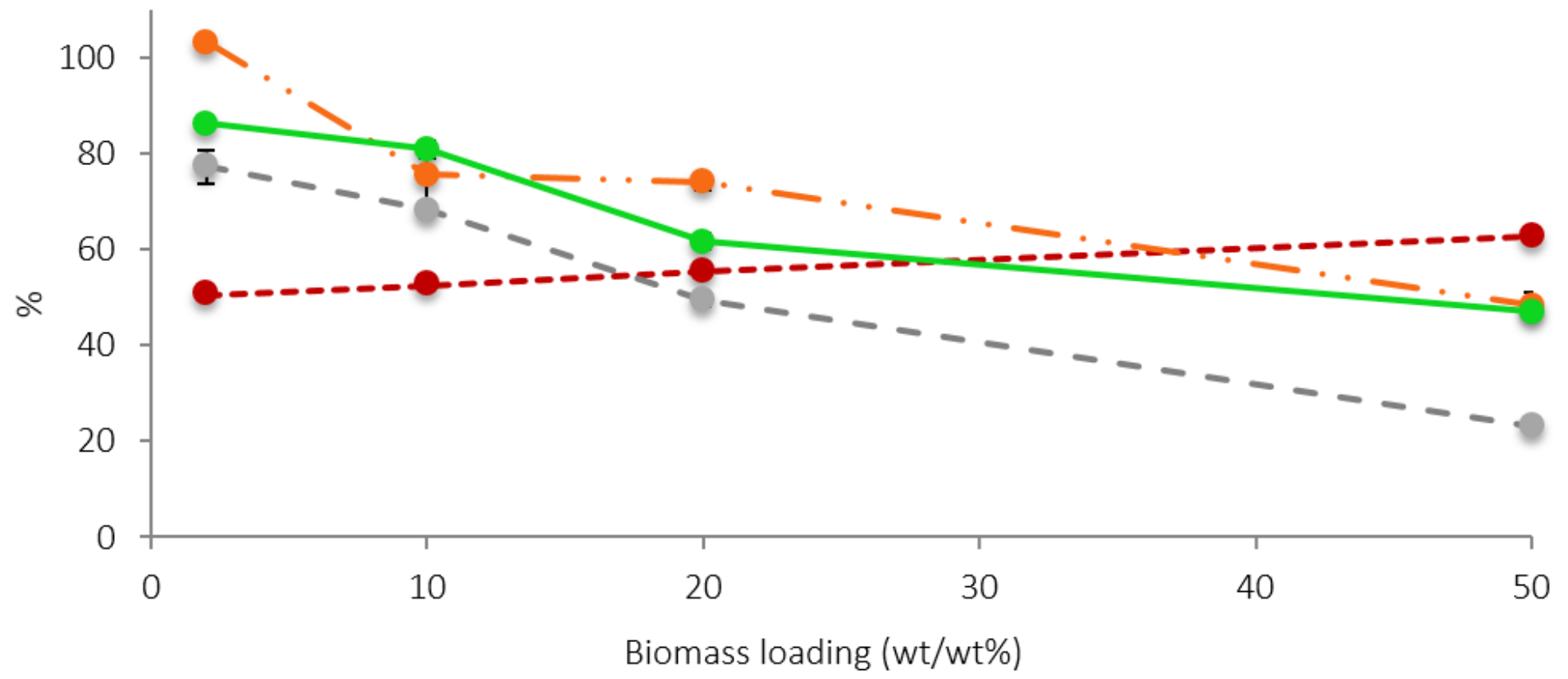

\section{Figure 1}

Pulp, lignin and saccharification yields and pulp delignification after pretreatment of Miscanthus with [TEA][HSO4] with a final water content of $20 \mathrm{wt} \%$ for $6 \mathrm{~h}$ at $120^{\circ} \mathrm{C}$ and biomass to solvent ratios ranging 
from $1: 50$ to $1: 2 \mathrm{~g} / \mathrm{g}$, corresponding to loadings from 2 to $50 \mathrm{wt} \%$. Errors were calculated as standard deviation across triplicates.

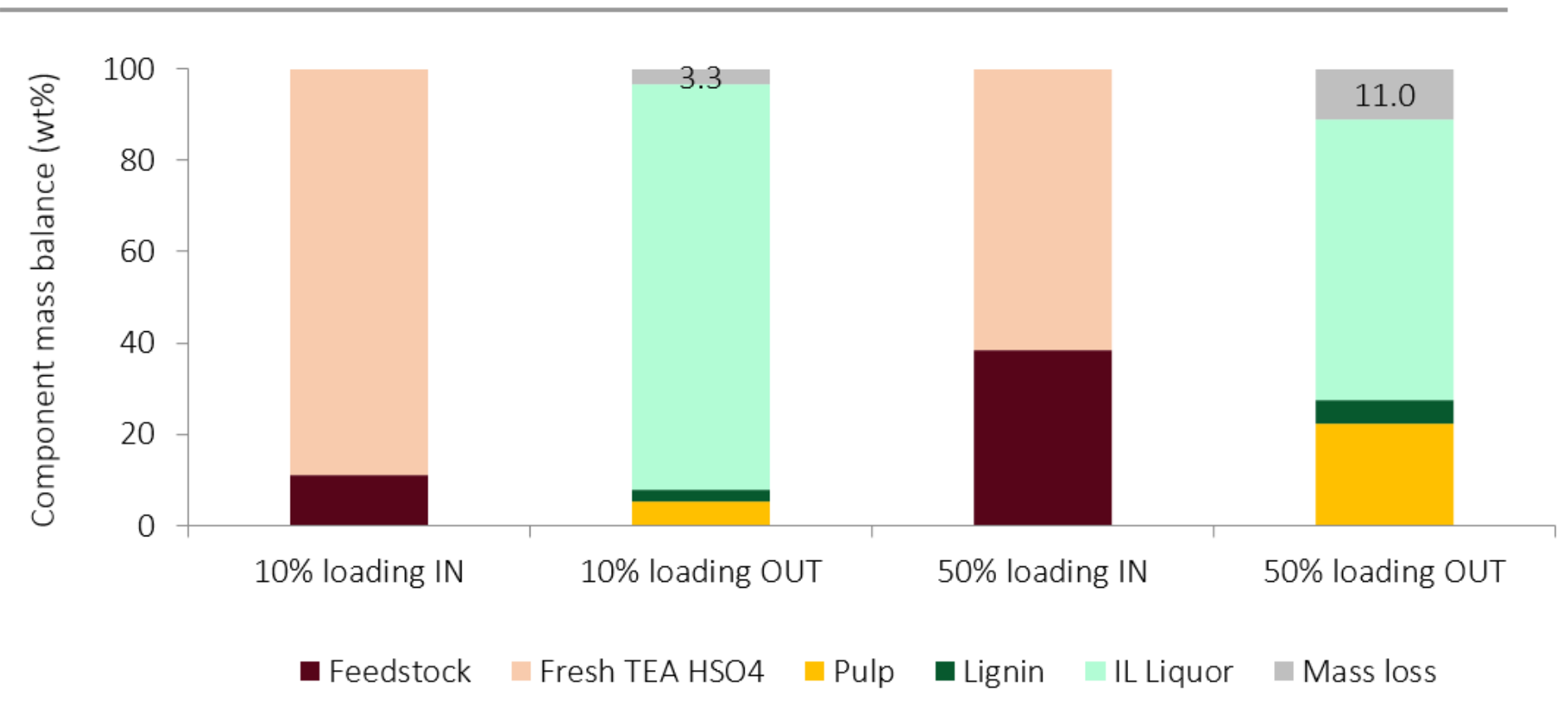

Figure 2

Total component mass balance for experiments conducted at $10 \mathrm{wt} \%$ and $50 \mathrm{wt} \%$ biomass loading. Results are shown per $100 \mathrm{~g}$ of starting material on a dry basis, assuming no IL losses.

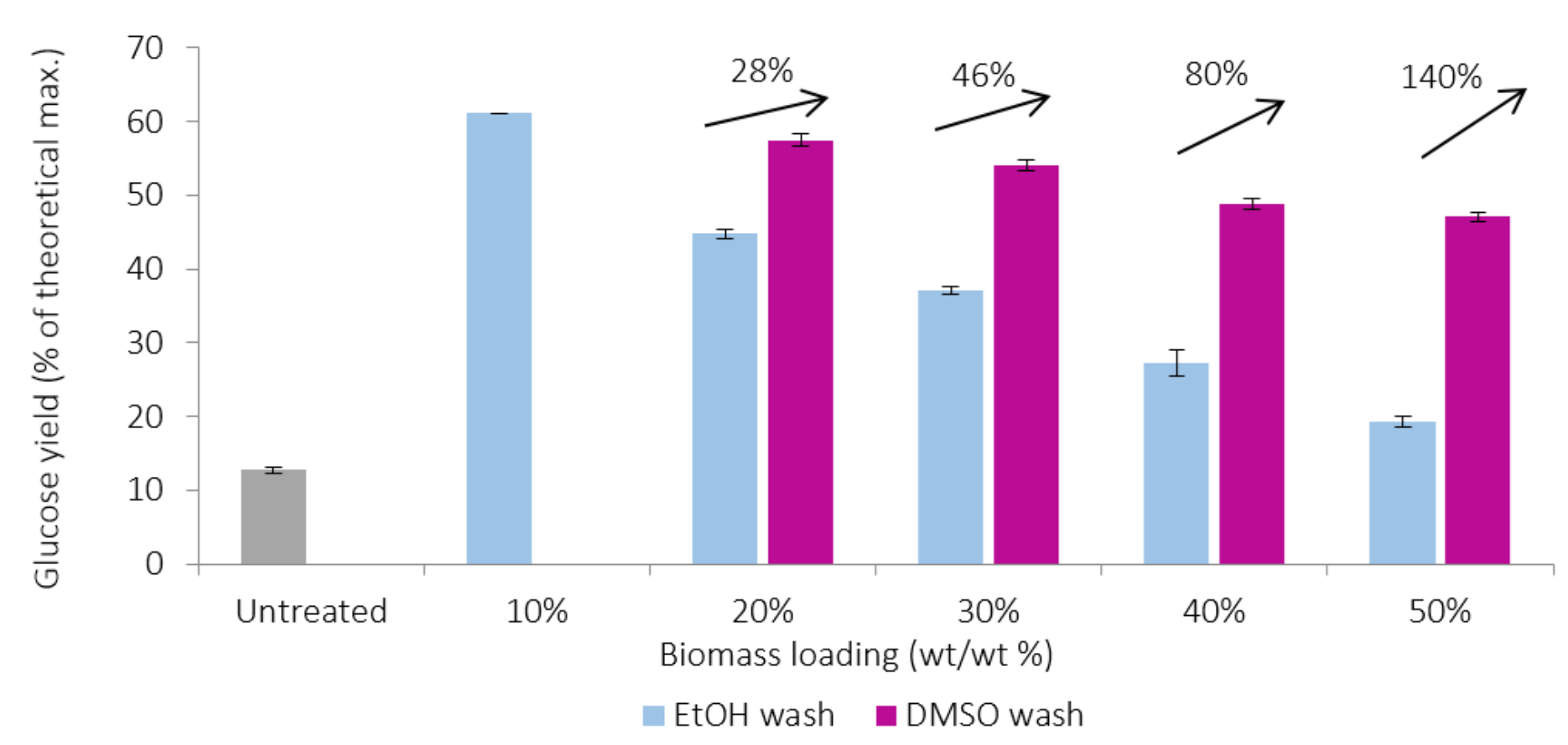

Figure 3

Glucose yields obtained after four ethanol washes (ethanol wash) and four ethanol washes plus one DMSO wash (DMSO wash) of air-dried pretreated Miscanthus pulps at various biomass loadings. 
Enzymatic hydrolysis was carried out for 7 days and glucose yields are shown relative to the amount of glucan in untreated biomass. Percentage increase following DMSO wash relative to ethanol wash is shown inset.

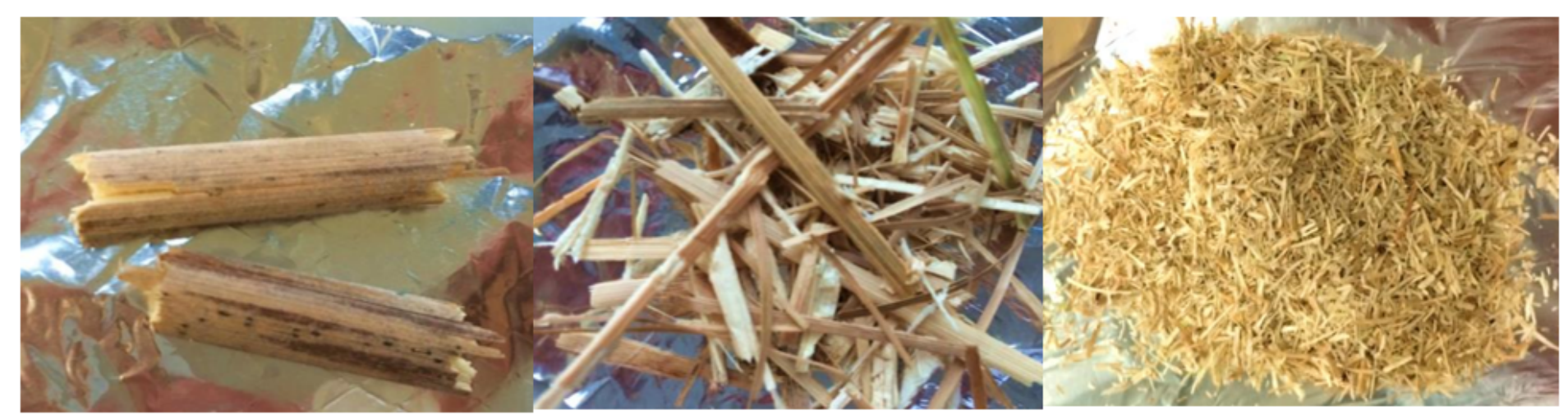

Coarse

Medium

Fine

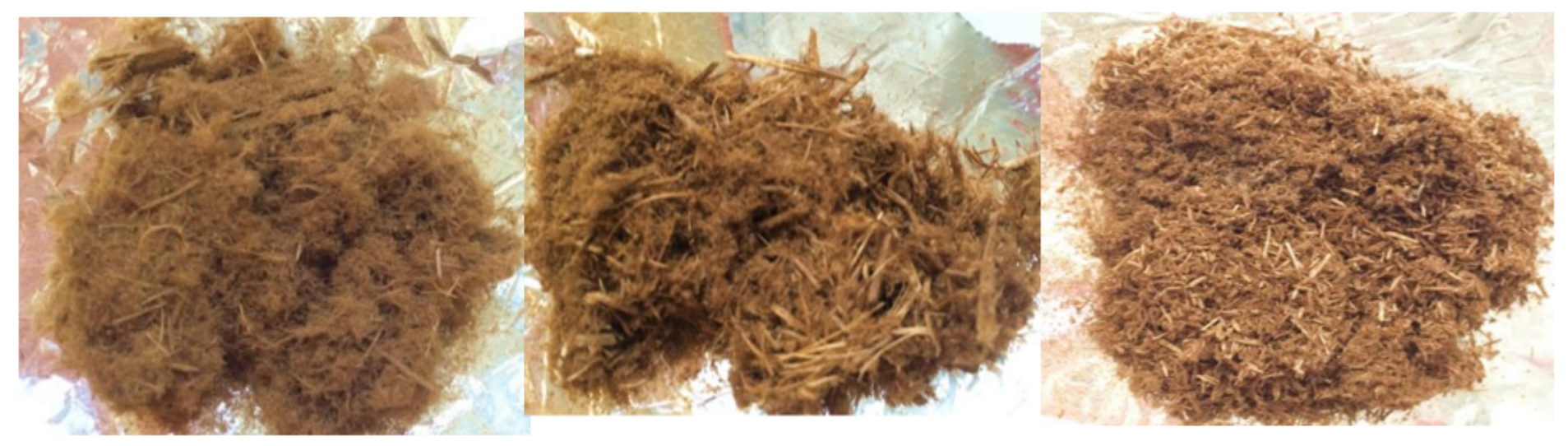

\section{Figure 4}

Photographs of (above) untreated biomass and (below) recovered pulps after pretreatment of Miscanthus with [TEA][HSO4] at $120^{\circ} \mathrm{C}$ for 6 hours at bench scale using a biomass loading of $20 \mathrm{wt} \%$. 


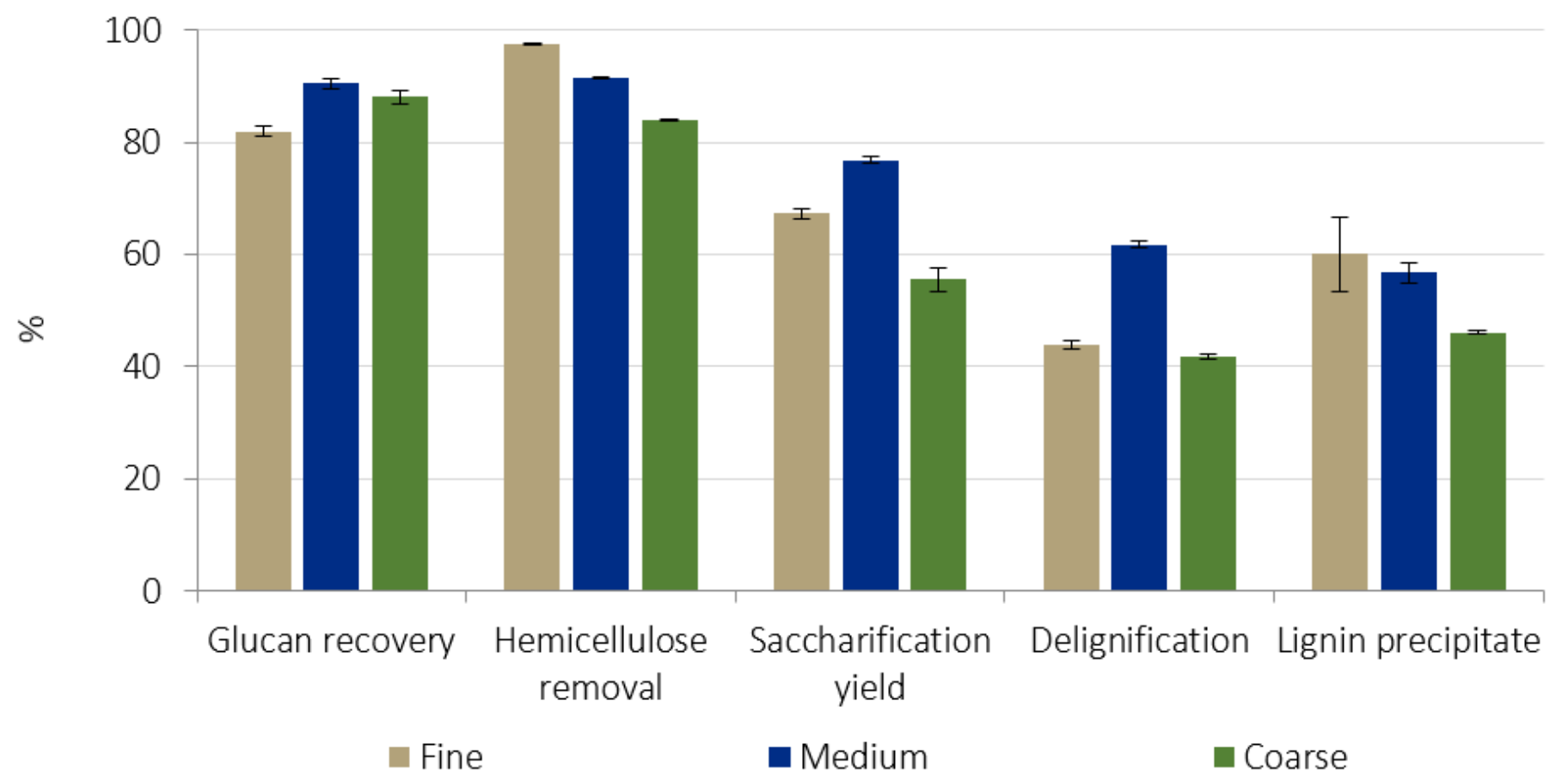

Figure 5

Effect of particle size of Miscanthus on key indicators for ionoSolv pretreatment, after pretreatment with [TEA][HSO4] at $120^{\circ} \mathrm{C}$ for 6 hours at bench scale using a biomass loading of $20 \mathrm{wt} \%$. 

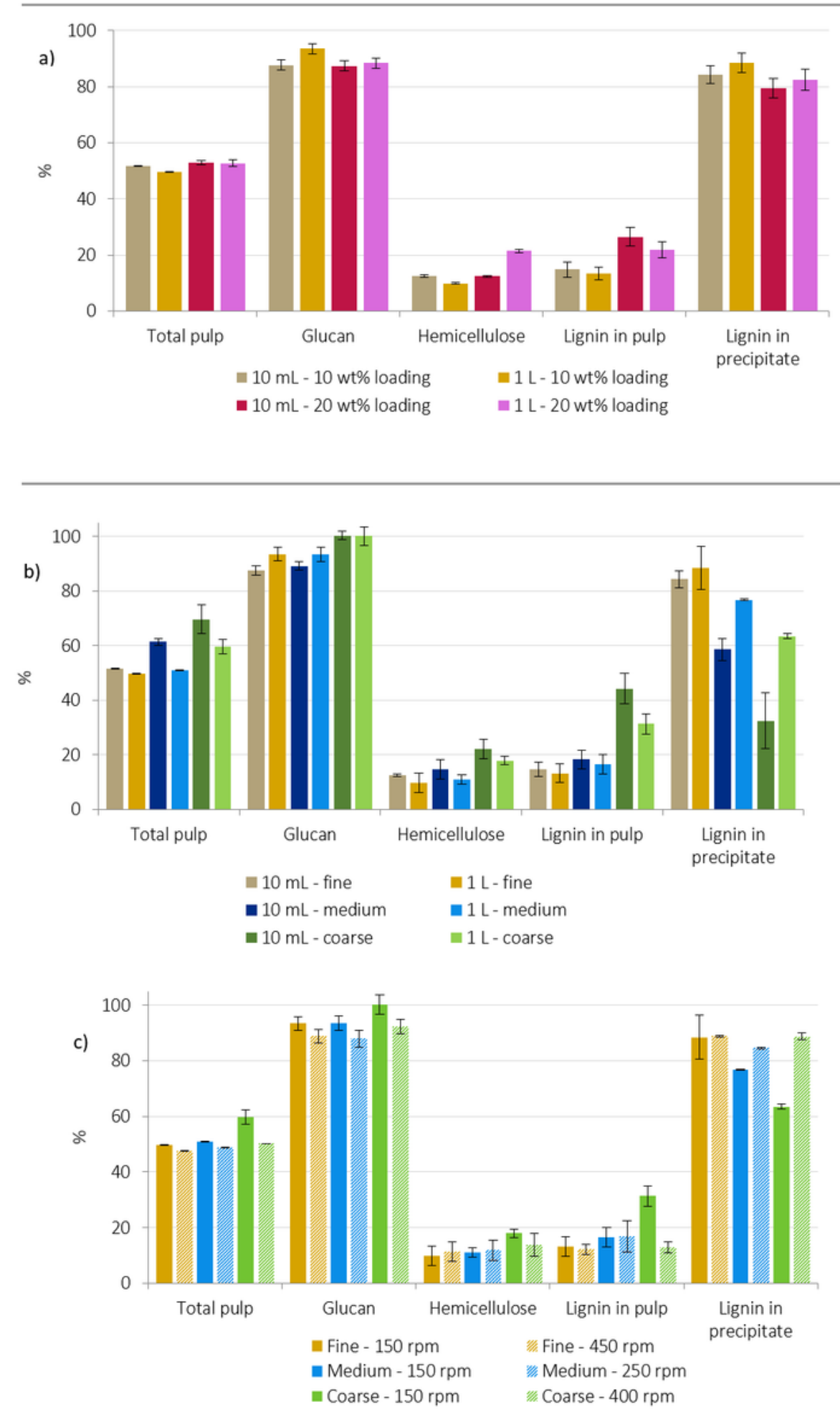

Figure 6

Comparisons of total solids (i.e. pulp), glucan, hemicellulose and lignin recovered in the pulp, and lignin precipitate yield (a) upon 100-fold scale-up for 10 and $20 \mathrm{wt} \%$ solid loading. Results shown as a proportion of component amount in untreated Miscanthus; (b) for fine, medium and coarse particle sizes. Results shown as a proportion of component amount in untreated Miscanthus; (c) for fine, medium and 
coarse particle sizes as a function of stirring speed. Results shown as a proportion of component amount in untreated Miscanthus.

\section{Supplementary Files}

This is a list of supplementary files associated with this preprint. Click to download.

- ESIScaleUppaperv4finalPDFsaved.pdf 